\title{
MELHORIA DE INDICADORES DE DESEMPENHO DE PRODUÇÃO EM UMA EMPRESA DE PEQUENO PORTE POR MEIO DE UM SISTEMA DE INFORMAÇÃO ERP GRATUITO
}

Data de submissão: 22/09/2017 Aceite: 02/08/2018

Luciana Fighera Marzall ${ }^{1}$ Lucas Almeida dos Santos ${ }^{2}$ Leoni Pentiado Godoy ${ }^{3}$ Vânia Medianeira Flores Costa ${ }^{4}$

\section{RESUMO}

Inseridas em um cenário mercadológico altamente competitivo, as micro e pequenas empresas defrontam-se com inúmeros obstáculos para se manterematuantes. Dados pesquisados revelam que $98 \%$ das empresas brasileiras são de micro e pequeno porte, o que mostra a sua importância para a economia nacional. Assim, é necessário empenho por parte dos gestorespara administrar de forma eficaz a rotina de trabalho, a fim de melhorar a gestão e consequentemente otimizar o desempenho destes empreendimentos. Visando aprimorar a gestão do processo produtivo de uma pequena empresa, o presente estudo tem como objetivo implantar um sistema de gestão ERP gratuito com foco na melhoria de indicadores de desempenho da produção. A pesquisa classifica-se como pesquisa-ação, com abordagem qualitativa e quantitativa, tendo como procedimento o estudo de caso. Como resultados foram averiguados indicadores antes, durante e depois da implantação do sistema ERP, concluindo que, através da mensuração,o sistema implantado trouxe melhorias ao desempenho da organização pesquisada.

Palavras-chave: Sistemas ERP. PCP.Micro e Pequenas Empresas.

1 Possui graduação em Administração pela Universidade Federal de Santa Maria, UFSM, mestrado em Engenharia de Produção pela UFSM e doutorado em andamento em Administração pela UFSM. Santa Maria - Rio Grande do Sul. Brasil. E-mail: lucimarzall@gmail.com 2 Possui graduação em Ciências Contábeis pela Universidade Franciscana, UFN, graduação em andamento em Administração pela Universidade Federal de Santa Maria, UFSM, mestrado em Engenharia de Produção pela UFSM e doutorado em andamento em Administração pela UFSM. Santa Maria - Rio Grande do Sul. Brasil. E-mail: luksanttos@gmail.com

3 Possui graduação em Administração, mestrado e doutorado em Engenharia de Produção pela Universidade Federal de Santa Maria, UFSM. Santa Maria - Rio Grande do Sul. Brasil. E-mail: leoni_godoy@yahoo.com.br

4 Possui graduação em Administração pela Universidade Federal de Santa Maria, UFSM, mestrado em Administração pela Universidade Federal de Santa Catarina, UFSC e doutorado em Administração pela Universidade Federal da Bahia, UFBA. Santa Maria - Rio Grande do Sul. Brasil. E-mail: vania.costa@ufsm.br 


\section{INTRODUÇÃO}

O aprimoramento do processo de gerenciamento é necessário e ocorre diariamente nas empresas. Os administradores baseiam suas ações em informações sobre a rotina organizacional, procurando adequar procedimentos em busca de melhoria de resultados sem contudo sucumbir às pressões provenientes da concorrência (MARQUES; OLIVEIRA, 2008).

A gestão de indicadores de desempenho vem ao encontro da ideia de gerenciamento, pois trata-se de uma estratégia empregada para otimizar processos, a qual foca no controle quantitativo do seu resultado, observando por meio de números a melhoria ou não das operações do empreendimento. Assim, para empresas industriais, é importante que a gestão de indicadores se estenda para o chão de fábrica, uma vez quedefinir o que deve ser medido e avaliado torna-se uma tarefa complexa, levando-se em consideração que ações realizadas em uma determinada área de atuação geram impactos em diversas áreas da empresa, demonstrando a interligação existente entre os setores (CALLADO; CALLADO; ALMEIDA, 2007).

Além da gestão de indicadores é importante perceber que a produtividade de uma organização industrial depende também do Planejamento e Controle da Produção (PCP). Para Vollmann et al. (2006), o PCP é um sistema de planejamento e controle que se ocupa em idealizar a influência de todos os aspectos da produção entre eles mesmos e o ambiente externo, incluindo o gerenciamento de materiais, programação de máquinas, gestão de pessoas e coordenação de fornecedores e clientes.

Para Santos (2013), o PCP é responsável pelo fluxo de informações de diversas áreas do sistema produtivo, tendo como foco a otimização do emprego de materiais e pessoas, o que faz deste uma atividade empresarial que envolve grandes quantidades de informações capazes de influenciar o rumo do negócio.

Os autores Turbanet al. (2010) e O'brien e Marakas (2013) explicam que o tipo de sistema de informações mais utilizado para gestão de empresas industriais é o Enterprise Resource Planning (ERP). Isso provém do fato do sistema abarcar a administração de materiais e custeio de produção. Cabe lembrar que o ERP é proveniente do sistema Material Requirement Planning (MRP), que é responsável por realizar o controle informatizado das necessidades de matérias primas e insumos de produção.

O'brien e Marakas (2013) explicam que o sistema ERP é uma evolução do MRP, sendo composto de um conjunto de aplicações capazes de integrar os processos empresariais de finanças, logística, suprimentos, manufatura, vendas e recursos humanos em um só sistema de informação, o que possibilita o registro de dados em um mesmo local de armazenamento interligando-os e, a partir disso, produzir informações em tempo real.

Turban et al. (2010) consideram altos os custos e riscos envolvidos no processo de implantação de sistemas ERP, bem como a sua complexidade. Assim, estes obstáculos devem ser analisados mediante a tomada de decisãoda implantação deste tipo de sistema.

As micro e pequenas empresas (MPE) têm se destacado em vários países devido à sua relevância econômica, principalmente, no que diz respeito à geração de empregos e renda, em um cenário de desaceleração da economia mundial (TEIXEIRA, 2017).

Para a autor, as MPEs dispõem de parcos recursos para aplicação em gestão, tornando-se frequentemente inviável a adoção de sistemas de gestão pagos, pois estas têm restrições financeiras, motivo que as impossibilita de assumir custos fixos elevados e de se responsabilizar com empreendimentos de alto risco financeiro. 
Assim, em busca de melhorar o resultado do processo de produção de uma indústria de pequeno porte, sem gerar custos, definiu-se como objetivo 'implantar um sistema de gestão ERP gratuito em uma empresa de pequeno porte com foco na melhoria de indicadores de desempenho da produção.'

A pesquisa se justifica, pois a aplicação de um sistema ERP pode auxiliar o desenvolvimento e consolidação de pequenas empresas. Do ponto de vista científico, o desenvolvimento deste estudo representa um progresso do aprofundamento teórico-conceitual sobre a empregabilidade de sistemas de gestão gratuitos e automatização de processos gerenciais em indústrias de pequeno porte por meio de sistemas de informação, trazendo um maior esclarecimento sobre o impacto da gestão da informação no resultado da organização e como isso se procede.

\section{REVISÃO DA LITERATURA}

Na revisão da literatura estão apresentados os conceitos e definições que deram o embasamento teórico necessário para o desenvolvimento deste trabalho.

\subsection{MICRO E PEQUENAS EMPRESAS (MPE)}

As microempresas e as empresas de pequeno porte, aqui generalizadas pelo termo micro e pequena empresa (MPE), distinguem-se pelo número de funcionários que emprega e pelo volume de faturamento anual (TEIXEIRA, 2017).

As MPEs se destacam no cenário econômico mundial e caracterizam-se pela criação de novos postos de trabalho, contribuindo para o desenvolvimento sócio-economico local. Deste modo as MPEs são elementos de crucial importância para o crescimento financeiro da cidade local, bem como auxilia a geração de emprego, transformando a realidade da região em que se instalam (SANTINI et al., 2015).

O Quadro 1 apresenta os critérios de classificação adotados pela economia brasileira para enquadramento de micro e pequenas empresas no Brasil.

Quadro 1: Enquadramento de porte das empresas brasileiras por número de colaboradores

\begin{tabular}{|c|c|c|}
\hline \multirow{2}{*}{ PORTE } & \multicolumn{2}{|c|}{ SETORES } \\
\cline { 2 - 3 } & INDÚSTRIA & COMÉRCIO E SERVIÇOS \\
\hline Microempresa & Até 19 pessoas empregadas & Até 9 pessoas ocupadas \\
\hline Pequena empresa & De 20 a 99 pessoas empregadas & De 10 a 49 pessoas ocupadas \\
\hline Média empresa & De 100 a 499 pessoas empregadas & De 50 a 99 pessoas ocupadas \\
\hline Grande empresa & 500 pessoas ocupadas ou mais & 100 pessoas ocupadas ou mais \\
\hline
\end{tabular}

Fonte: SEBRAE (2013).

É possível visualizar que a realidade das MPEs brasileiras é bastante difícil, devido à precariedade de sua gestão e restrição financeira. Elas operam com baixos montantes de capital, o que reduz o seu poder de barganha juntos aos clientes, fornecedores e órgãos financiadores. Também sofrem com a relação de complementaridade e subordinação com as empresas de grande porte, vivendo à luz das decisões destes grandes grupos. Por possuírem uma restrita capacidade de pagamento também têm dificuldades de acesso à financiamentos de capital de giro e empréstimos de longo prazo para investimentos (SANTINlet al., 2015). 
Os autores ainda comentam que a restrição de capital resulta em parco investimento em inovação tecnológica, o que influencia negativamente o seu desenvolvimento. Desta forma, as MPEs costumam permanecer à margem das melhorias como automatização de processos, ganho de produtividade e possibilidade de ampliação dos tipos de produtos e serviços oferecidos.

Ainda, as MPEs possuem altas taxas de natalidade e mortalidade, o que caracteriza a vulnerabilidade deste tipo de empreendimento, classificando-os como investimento de elevado risco para o empreendedor (MACHADO, 2010; SALES; BARROS; PEREIRA, 2011).

Nascimento et al. (2013), constataram que é complexo o problema dos elevados índices de mortalidade de micro e pequenas empresas. É frequente a ausência da distinção das finanças pessoais do empreendedor e das finanças corporativas. Em termos contábeis e econômicos (pessoa física e jurídica), esta relação financeira prejudica a mensuração do lucro ou prejuízo operacional do negócio. Ainda, os registros contábeis são pouco adequados, ocultando o resultado real do empreendimento. Outro problema de gestão é a forte atuação dos proprietários, o que torna o poder decisório centralizado e de estreito vínculo entre os sócios, tornando a gestão mais emocional do que racional.

Uma dificuldade comum às MPEs se refereà mão de obra empregada. É corriqueira a utilização de familiares no gerenciamento, mesmo que estes indivíduos não tenham a qualificação necessária para ocupar os seus cargos. Este fato se dá na restrição do orçamento para pagamento de salários adequados ao mercados, reduzindo a produtividade da empresa.

Apesar das dificuldades supracitadas, as informações coletadas sobre MPEs corroboram com o fato de que existem inúmeros cidadãos brasileiros que empreendem e movimentam a economia do país de forma expressiva.

No Quadro 2, observa-se que do total das empresas formalizadas no Brasil, $98 \%$ são MPEs, porém elas são responsáveis apenas por $27 \%$ do PIB do País.

Quadro 2: Representatividade das MPEs na economia brasileira

\begin{tabular}{|l|c|}
\hline \multicolumn{1}{|c|}{ VARIÁVEL } & REPRESENTATIVIDADE ECONÔMICA \\
\hline Número de empresas & $98 \%$ \\
\hline Geração de empregos & $59 \%$ \\
\hline Faturamento & $28 \%$ \\
\hline PIB & $20 \%$ \\
\hline Número de empresas exportadoras & $29 \%$ \\
\hline Valor das exportações & $1,7 \%$ \\
\hline
\end{tabular}

Fonte: FGV (2013).

A FGV (2013) afirma que os pequenos negócios empregam 59\% da mão de obra formal no Brasil e respondem por $40 \%$ da massa salarial do país, confirmando a relevância das MPEs para a economia, auxiliando a geração de empregos e movimentação econômica do Brasil. Lamentavelmente, os dados demonstram a baixa rentabilidade destas organizações, o que mostra que existe a necessidade de aprimoramento na gestão.

\subsection{SISTEMAS ERP}

A tendência da área de sistemas de informação não é apenas visualizar a empresa em setores ou ações isoladas, mas sim enxergar a organização como um todo, a fim de melhorar o seu desempenho (PADILHA; MARINS, 2005). Com base nesta premissa os sistemas ERP, surgiram 
trazendo como apelo a integração de informações empresariais e agilidade na execução e controle de processos.

Esteves e Pastor (1999a) conceituam sistemas ERP como um pacote de sistemas de informaçãocomposto por vários módulos de operação, tais como produção, vendas, finanças e recursos humanos, que se integram através de um banco de dados com informações de todos estes processos, interligando-as e gerando informações em tempo real, nos quais os módulos podem ser customizados para atender a necessidade de seus usuários.

Chopra e Meindel (2003) explicam o sistema ERP como um sistema integrado, que possibilita um fluxo de informações único, contínuo e consistente por toda a empresa, sob uma única base de dados. É um instrumento para a melhoria de processos de negócios, como a produção, compras ou distribuição, gerando e registrando informações em tempo real. Em suma, o sistema permite visualizar por completo as transações efetuadas pela empresa, desenhando um amplo cenário de seus negócios.

Em relação ao impacto de sistemas de ERP nas organizações, Davenport (1994) já se referia ao sistema como o desenvolvimento mais importante no uso corporativo de tecnologia da informação da década de 90.0 autor explica que o ERP é constituído por módulos operacionais, nos quais os dados utilizados são armazenados na base central. Esta base central pode ser manipulada por informações provenientes de todos os módulos, na ocorrência de interação entre os processos.

Sistemas ERP têm um ciclo de vida que consiste nas diversas etapas pelas quais passam um projeto de desenvolvimento e utilização. Para descrever o ciclo, foi empregado o modelo de Esteves e Pastor (1999b), mais tarde reconstruído por Zwicker e Souza (2003), que utilizaram quatro etapas de desenvolvimento do ciclo. Inicialmente, decide-se pela implantação de um sistema ERP como solução para as necessidades de informação da empresa. Na Figura 1, visualiza-se o ciclo de um sistema ERP.

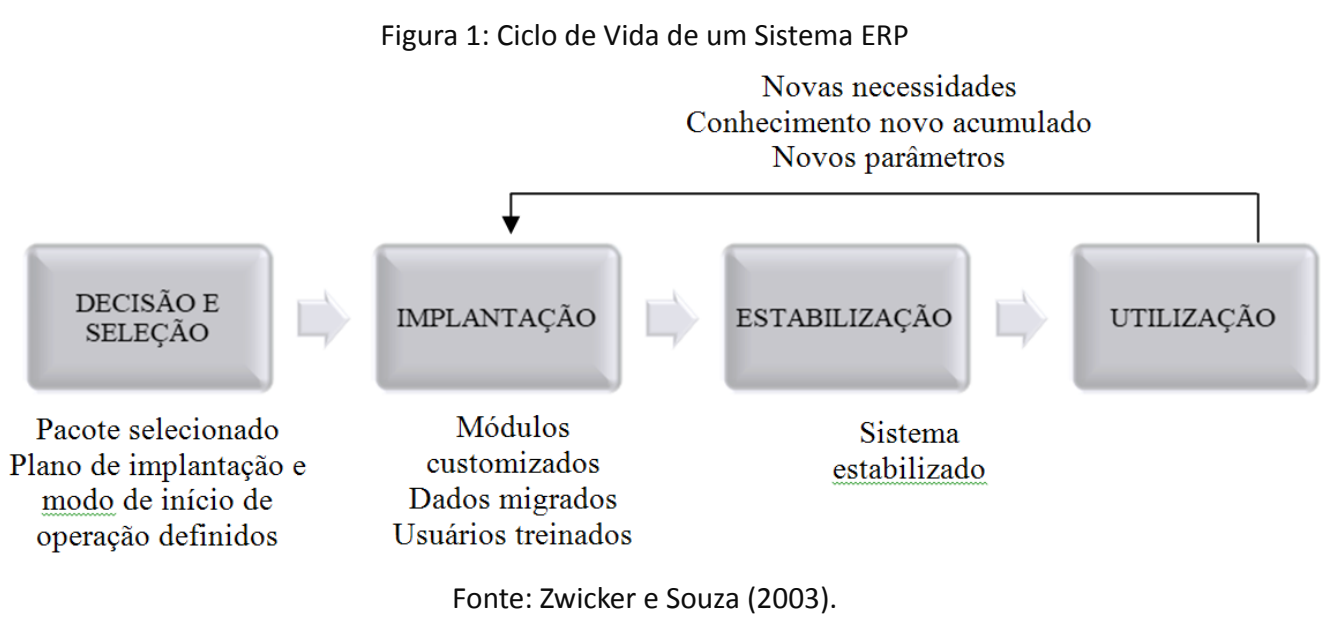

Após a decisão do emprego do ERP e seleção do software, realiza-se o planejamento da implantação, que engloba o estabelecimento dos objetivos, escopo do projeto, metas, métricas, responsabilidades e a estratégia de desenvolvimento do projeto. A estratégia de implantação envolve a definição do modo de início de operação, das atividades que serão realizadas e o cronograma, o qual se deve incluir considerações sobre prazos e recursos (ZWICKER; SOUZA, 2003).

A implantação é o segundo passo do ciclo de vida do ERP. Esta é uma das etapas mais críticas devido às mudanças profundas nos processos organizacionais e nas relações de trabalho (WOOD; CALDAS, 1999; NORRIS; HURLEY, 2001; ZWICKER; SOUZA, 2003).

$\mathrm{Na}$ implantação os módulos do sistema são colocados em funcionamento pela primeira 
vez, sendo preciso mapear e adaptar os processos de negócio ao software, realizando as customizações necessárias. Este procedimento é denominado parametrização. Na parametrização também é realizada a conversão dos dados e carga de informações iniciais, gerando a configuração do hardware e do software. Esta etapa contempla tarefas que vão do término da elaboração do plano de implementação até o início da operação do ERP, quando, este passa a ser uma ferramenta de gestão de informação definitiva da empresa (PADILHA; MARINS, 2005).

Zwicker e Souza (2003) explicam que, assim que for iniciada a operação do sistema no empreendimento, também se inicia a etapa de estabilização. Neste momento, o ERP se torna um objeto concreto e passa a fazer parte da rotina do negócio. A estabilização é o momento que se empregam os maiores esforços em termos de gerenciamento e técnicas, pois é neste período que surgem as maiores dúvidas e a ocorrência de uma infinidade de erros que, geralmente, são ainda desconhecidos pelos operadores. Assim, os usuários compreendem o processo por inteiro e percebem que a empresa depende do sistema para as suas atividades, o que aumenta a pressão para que os problemas sejam rapidamente resolvidos.

A última etapa é a utilização, isto é, o ERP se torna parte intrínseca das operações da empresa. Ter o sistemafuncionamento não significa que ele está sendo utilizado por completo ou que está sendo empregado corretamente pelos usuários, porém os operadores já distinguem a sua responsabilidade sobre as tarefas e as necessidades de ajustes. Através dessa ferramenta, os gestores compreendem os procedimentos da rotina de trabalho e conhecem a cadeia de valor da organização, possuindo assim um maior número de informações de apoio à decisão (ZWICKER; SOUZA, 2003).

\section{METODOLOGIA}

Este tópico explica o conjunto de normas, procedimentos e regras estabelecidos para a realização da pesquisa. Empregou-se, inicialmente, a pesquisa bibliográfica, pois oferece suporte em relação à escolha do problema, aos objetivos determinados, além de fundamentar a justificava do tema proposto através de materiais publicados em livros, revistas, jornais e redes eletrônicas (GIL, 2010).

Este trabalho é um estudo de caso, pois foi realizada umaprofunda e exaustiva investigação do processo relatado, produzindo, assim, um amplo e detalhado conhecimento, com o objetivo de perceber "como" e "por que" funcionam as "coisas". Portanto, é umaanálise empírica que buscou compreender o fenômeno dentro do seu contexto (YIN, 2010).

A natureza de pesquisa é pesquisa-ação, pois, aprimorou-se a prática, explorando o processo e agindo sobre ele. Na pesquisa-ação, o agente pesquisador também é ator da pesquisa, modificando seus resultados e da realidade local (TRIPP, 2005; TOZONI-REIS, 2007).

Quanto aos objetivos, considera-se este estudo como exploratório e descritivo, pois se buscou explorar e narrar as características de um determinado processo e do estabelecimento de relações variáveis, bem como auxiliar na resolução de problemas, melhorando suas práticas (THOMAS; NELSON; SIVERMAN, 2007).

Foi empregada abordagem qualitativa no mapeamento do processos e delineamento do problema de pesquisa, bem como análises quantitativas para verificar a eficácia do método aplicado. Para Fleury (2012), a pesquisa quantitativa se utiliza de números para traduzir opiniões e informações, analisando-as e classificando-as por meio deles. A pesquisa qualitativa se caracteriza por obter dados específicos sobre um grande número de variáveis, proporcionando ao leitor a oportunidade de examinar a experiência relatada no estudo (STAKE, 2013). 
Para a coleta de dados foi utilizada a pesquisa documental, observação participante, ferramentas gerenciais estruturadas, além de conversas e entrevistas não padronizadas com os responsáveis pelo andamento da pesquisa. A Figura 2 mostra como foi estruturado o método.

Figura 2: Método de pesquisa
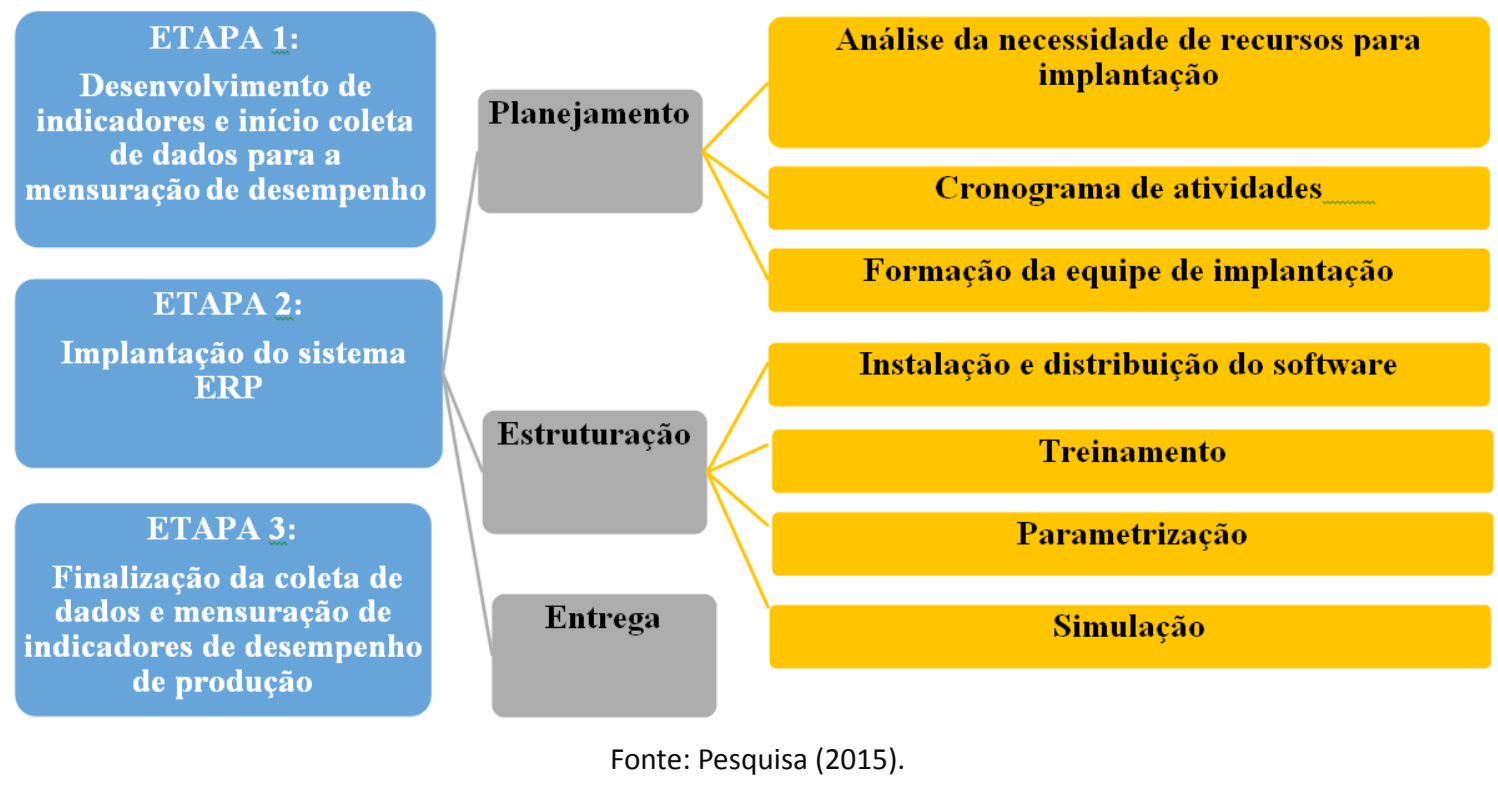

A fim de atingir o objetivo da pesquisa, detalhou-se na Figura 2 o progresso do estudo em 3 etapas. Inicialmente, desenvolveram-se os indicadores de desempenho que serviram com elemento de verificação da eficácia da implantação do sistemaERP. A mensuração dos indicadores se deu durante o desenvolvimento da pesquisa, com a finalidade de criar um histórico dos índices mensurados e avaliar sua evolução.

A segunda etapa tratou da implantação do sistema de informação escolhido, sendo considerada a mais longa e complexa da pesquisa. Na fase final, encerrou-se a coleta e análise dos dados para a verificação da eficácia do sistema de gestão implementado. Como objeto de estudo, utilizou-se uma empresa de pequeno porte do setor industrial metal mecânico da região central do Estado do Rio Grande do Sul. A organização tem mais de 20 anos de atuação na área e conta com 19 colaboradores no seu quadro funcional.

\section{DISCUSSÕES E RESULTADOS}

Em princípio, foram mapeados os processos a fim de entender o funcionamento dos setores, a atuação dos colaboradores, os procedimentos de produção e as técnicas de gestão empregadas pela organização.

No departamento de produção,observou-se a ausência de um sistema de informação específico que integrasse as tarefas relativas à fabricação de produtos e gestão de insumos de produção. $\mathrm{O}$ que foi diagnosticado por meio da pesquisa documental foi a existência de umsistema de informação que atendia a áreafinanceira, porém este não abrangiao planejamento e controle de produção. Os documentos geradospelo sistema financeiro eram adaptados para a gestão da produção até o momento da presente pesquisa. A adaptação ocorria da seguinte for- 
ma: o documento denominado "pedido de venda" era destinado ao gerente da fábrica, quando ocorria a venda de algum produto. De posse deste documento, o gerente fazia o planeamento da produção dos itens encomendados pelos clientes.Porém,este formulário não possuía dados sobre os itens que compõe a estrutura do produto a ser fabricado, bem como não descrevia as operações de produção, apresentando somente dados específicos do setor comercial, como modelo do produto, quantidade, cliente, valor e prazo de pagamento.

Desta forma, o setor deprodução ficava desprovido de informações importantes sobreaconstrução dos produtos, pois era desconhecida a quantidade exata de matéria prima necessária para confeccionar um modelo específico e não havia um controle informatizado da disponibilidade dos materiais no estoque. Oprocesso de fabricação era dependente dos montadores industriais mais antigos da empresa, que conhecem as etapas de produção e os materiais necessários à construção de cada produto.

O fato de não haver um controle informatizado de materiais contribuía para a geração de uma lacuna de tempo entre a entrada do pedido na produção e a efetiva iniciação do processo de fabricação, pois o responsável pelo setor de estoques não tinha um planejamento prévio dos itens que ele deveria manter armazenados para atender a demanda de produtos da época. Isto gerava atrasos de produção, pois tudo era organizado no momento que o cliente executava a compra de produtos e muitas vezes a matéria prima necessária para iniciar a produção demorava mais de 10 dias para chegar nas instalações da empresa pesquisada. A Figura 3 mostra o momento da ocorrência do atraso do início da produção dentro do fluxo dos processos relacionados ao PCP.

Figura 3: Mapeamento do fluxo gerador dos atrasos de pedidos.

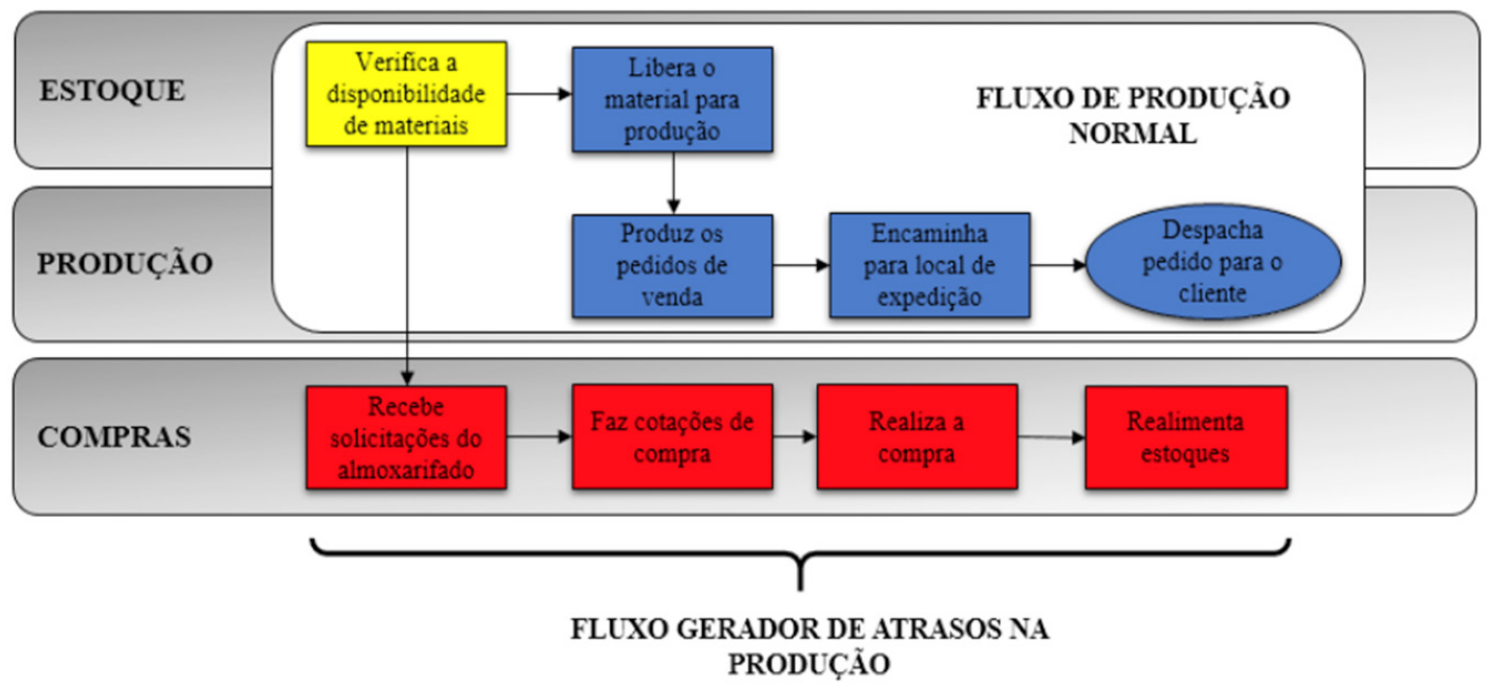

Fonte: Pesquisa(2015).

O sistema utilizado tampouco registrava a saída de itens do estoque no momento fabricação. Esta situação tornavainválido o controle informatizado de movimentação dos itens, pois os produtos não saiam do estoque caso não houvesse uma baixa realizada manualmente, 0 que não era feito pelos operadores do antigo sistema.

Também foi verificado, por meio de entrevistas não estruturadas, que a empresa pesquisada costumava utilizar um sistema ERP pago em anos anteriores ao estudo. Porém, a empresa que fornecia o sistema foi incorporada por uma organização mundial de sistemas de informação 
(TOTVS) e o software utilizado se tornou muito caro, fazendo com que as mensalidades e upgrades anuais obtivessem acréscimos de mais de $300 \%$ no valor cobrado. Assim, a empresa optou por descontinuar ouso do ERP pago, perdendo os controles informatizados de gestão de materiais e processos de produção. $O$ fato da empresa já ter utilizado anteriormente um ERP facilitou a adoção do tema da pesquisa pela empresa, pois os usuários do programa reconheceram queperderamalguns benefícios mediante o abandono do ERPpago, apoiando assim a aplicação do estudo a fim de aprimorar a gestão do negócio.

Ao final das presentes análises, verificou-se uma real necessidade de uma gestão mais aprimorada de recursos materiais e processos produtivos, definindo-se como objetivo de pesquisa "implantar um sistema ERP gratuito com foco na melhoria de indicadores de desempenho de produção".

Em função do tempo restrito para a execução da pesquisa, o escopo de implantação foi limitado aum produto escolhido do portfólio da empresa e implantação de três módulos de um sistema ERP. Assim, foi selecionadaa antena modelo "PV215027" (a empresa possui mais de 200 modelos diferentes de produtos), porque esta representava o maior percentual de faturamentodo últimos 12 meses de operação (entre 2014 e 2015). Os módulos a serem implantados foram: manufatura, estoques e compras, pois foram identificados pelo pesquisador como os processos mais voltados para gestão de produção e materiais dentro de um sistema ERP.

Em seguida, foram desenvolvidos os indicadores de desempenho de produção e criado o instrumento de coleta de dados. Os indicadores surgiram das ideias compiladas em uma reunião de brainstorming com os colaboradores da área de vendas, produção e estoques. A maioria dos colaboradores citou os atrasos de produção como o problema mais crítico da empresa. Assim, desenvolveram-se dois indicadores que visaram mensurar o tempo de atraso de produção (em dias) e a quantidade de pedidos em atrasos (em percentual), decorrentes da falta de materiais no estoque. No Quadro 3, descreve-se os indicadores de desempenho construídos na presente pesquisa.

Quadro 3: Indicadores de produção

\begin{tabular}{|c|c|}
\hline INDICADOR DE DESEMPENHO & FORMA DE CÁLCULO \\
\hline Tempo médio de atraso de produção & Total de dias de atraso / total de pedidos atrasados do mês \\
\hline Quantidade média pedidos em atraso & Total de pedidos atrasados/ total de pedidos emitidos no mês \\
\hline
\end{tabular}
Fonte: Pesquisa (2015).

A mensuração dos indicadores ocorreu da seguinte maneira: o responsável pelo setor de estoques recebeu em mãos uma planilha que relacionava todos os componentes necessários à da antena PV215027. A cada encomenda desta antena que entrava na empresa, oestoquista anotava na planilha a data de entrada do pedido na produção e neste momento se dirigia para a separação dos itens no estoque. Quando não era encontrado no estoquealgum componente da antena no momento da produção, assinalava-se o item na planilha,que era imediatamente encaminhada ao setor de compras para a aquisição do produto faltante.

Quando o material faltante chegava na empresa, era escrito na planilha a data do recebimento do material e media-se a lacuna de tempo entre a entrada do pedido na fábrica e a chegada dos materiais na empresa, mensurando o tempo de atraso do início efetivo do processo produtivoe a quantidade de pedidos atrasados em relação à falta de materiais. A coleta ocorreu a cada encomenda de antenas modelo PV215027, durante o período de 8 meses (entre março de 2015 a outubro de 2015). 
Concomitantemente à coleta de dados, especificamente no período de junho a agosto de 2015, executou-se a implantação do sistema ERP na empresa. Para tal, foi escolhido umsistema de informação gratuito, conforme o propósito do projeto. A implantação ocorreu em três fases: planejamento, estruturação e entrega. No planejamento, foram relacionadas as tarefas para o cumprimentodo escopo do projeto, conforme mostra o Quadro 4.

Quadro 4: Atividades de implantação do sistema ERP

\begin{tabular}{|c|l|}
\hline ESTRUTURAÇÃO DO PROJETO & \multicolumn{1}{c|}{ ATIVIDADES } \\
\hline \multirow{5}{*}{ Instalação } & $\begin{array}{l}\text { Instalar banco de dados e software no servidor da empresa } \\
\text { Cadastrar acessos (chave e senha) para os operadores } \\
\text { Averiguar os módulos e equiparar aos processos do escopo } \\
\text { Estudar a operação dos módulos } \\
\text { Agendar os treinamentos de acordo com os horários disponíveis } \\
\text { Executar o treinamento dos usuários }\end{array}$ \\
\hline \multirow{5}{*}{ Parametrização } & $\begin{array}{l}\text { Revisar características gerais dos materiais utilizados (físico, químicas, marca...) } \\
\text { Agrupar os produtos por família de materiais e grupos de estoques } \\
\text { Estruturar os códigos e a nomenclatura de cadastro de produtos } \\
\text { Cadastrar os produtos e demais cadastros relacionados } \\
\text { Levantar e cadastrar a estrutura de materiais da antena PV215027 }\end{array}$ \\
\hline Simulação & $\begin{array}{l}\text { Relacionar os módulos implantados e executar a simulação de cada um deles } \\
\text { Simular um ciclo completo de operação de todos o módulos juntos e revisar erros }\end{array}$ \\
\hline
\end{tabular}

Fonte: Pesquisa (2015).

O programa escolhido foi o OpenERP, pois além de ser gratuito, também é utilizado por empresas renomadas como a Danone. Outro fator de escolha foi queeste sistemapossui uma comunidade na internet que compartilha tutoriais e experiências da sua utilização, que serviram de base para sua instalação e treinamentos na empresa pesquisada. Além disso, deu-se ao fato do programa possuir versão em português, o que o tornou mais compreensível e intuitivo aos usuários.

Logo, foi formada uma equipe para execução da implantação,designandoas responsabilidades de cada colaborador dentro do projeto. Foi determinado pelos diretores da empresa que as atividades de implantação não deveriam demandar mais do que duas horas diárias de cada envolvido, para não interferir no andamento das atividades da rotina de trabalho. Assim, foram alocados cinco pessoas para compor a equipe de implantação:gestor de TI, gestor de produção,gestor de compras, estagiário de área de produção e o pesquisador,o que totalizou 720 horas de trabalho destinados ao projeto. O prazo estabelecido para implantação foi de junho a agosto de 2015, contabilizando o total de três meses.

A primeira ação da implementação do sistema foi a instalação do banco de dados do ERP no servidor. Para tal, foram utilizados tutoriais baixados da internet fornecidos pela desenvolvedora do OpenERP. O gestor de TI cadastrou e classificou os usuários de acordo com a hierarquia de responsabilidade de cada um, dividindo-osem administradores e operadores.Os administradores ficaram com acesso atodas as áreas do sistema, enquanto os operadores ficaram restritos aos módulos aos quais eles operavam ou necessitavam ter acesso.

As restrições não foram definidas plenamente nesta fase, pois ainda não existiam informações muito específicas sobre o trabalho de cada usuário dentro do sistema. Mediante a definição dos acessos, instalação dos módulos operacionais e registro dosoperadores, iniciou-se a fase de treinamento do sistema, que ficou sob responsabilidade do pesquisador e ocorreu entre a 4a e 9a semana do projeto. Para o planejamento dos treinamentos, o conteúdo foi dividido e 
destinado a cada usuário de acordo com o número de horas que o mesmo tinha disponível para a implementação do ERP.

A tarefa seguinte foi equiparar os processos do projeto (produção, manufatura e compras) com os módulos operacionais do sistema escolhido. Foram estudadas as funcionalidades do sistema verificando quais eram os módulos que correspondiam aos três processos definidos no escopo. Assim, iniciou-se a parametrização, momento em que ocorreu a transcrição das operações realizadas na rotina de trabalho para dentro do programa, sendo necessário fazer análises do resultado de cada intervenção executada.

Este foi o período no qual se ajustou as funcionalidades, alinhando ERP aos requisitos e características da empresa.Primeiramente, houve um levantamento documental dos produtos existentes no estoque, com o intuito de classificá-los. Esta etapa foi necessária, pois o OpenERP se utiliza de categorias para classificação dos produtos, sendo necessário criá-las para gerir os materiais.

Para tal, os grupos de estoques foram divididos por características como: tipo de matéria prima, estrutura, forma, emprego, unidade de medida e durabilidade. Os dados sobres os materiais foram obtidos através das notas fiscais de compras e de relatórios de estoque físico.

Finalizado o desenvolvimento da hierarquia de materiais, ocorreu a montagem da nomenclatura e dos códigos dos itens comprados e fabricados. Para a diferenciação dos materiais, foi criado um modelo de nomenclatura padrão, que padronizou o processo de nomeação dos produtos, pois cada material precisa ter um nome e um código para a sua entrada e movimentação no sistema. O Quadro 5 apresenta a formação da hierarquia de materiais.

Quadro 5: Formação da Hierarquia de Materiais

\begin{tabular}{|c|c|c|}
\hline GRUPOS DE ESTOQUE & DESCRIÇÃO & CATEGORIAS DE PRODUTOS \\
\hline MATÉRIAS PRIMAS & $\begin{array}{l}\text { Materiais comprados que integram } \\
\text { diretamente o produto fabricado } \\
\text { pela empresa ou ferramentas de } \\
\text { desgaste rápido }\end{array}$ & $\begin{array}{l}\text { Metais /Fixadores/ Vedantes/ } \\
\text { Tratamentos de superfície/ Cabos/ } \\
\text { Soldas/ Óleos/ Gases de corte/ } \\
\text { Pastilhas/ Fresas/ Ferramentas de } \\
\text { desgaste rápido }\end{array}$ \\
\hline MATERIAL DE CONSUMO & $\begin{array}{l}\text { Materiais utilizados para dar suporte } \\
\text { aos processos de produção, porém } \\
\text { não compõe os produtos fabricados }\end{array}$ & $\begin{array}{l}\text { Gás para empilhadeira/ Óleos } \\
\text { lubrificantes e lubrificantes/ Graxas/ } \\
\text { Álcool/ Lixas/Serras/ Escovas/ Panos de } \\
\text { estopa/ Pastas térmicas/ Material de } \\
\text { expediente/ Material de limpeza }\end{array}$ \\
\hline PRODUTO ACABADO & Produtos fabricados pela empresa & $\begin{array}{l}\text { Antenas/ Jumpers/ Supressores de } \\
\text { surto }\end{array}$ \\
\hline PRODUTOS INTERMEDIÁRIOS & $\begin{array}{l}\text { Subprodutos que integram o produto } \\
\text { final fabricado pela empresa }\end{array}$ & $\begin{array}{l}\text { Suportes/Linhas/ Refletores/ Pinos/ } \\
\text { Buchas/Conectores/ Dipolos }\end{array}$ \\
\hline ATIVO IMOBILIZADO & $\begin{array}{l}\text { Bens e direitos de natureza } \\
\text { permanente que são utilizados para } \\
\text { a manutenção das atividades da } \\
\text { empresa }\end{array}$ & $\begin{array}{l}\text { Mesas/ Cadeiras/ Computadores/ } \\
\text { Instalações/Veículos/Softwares/Máquinas } \\
\text { e equipamentos/ Ferramentas duráveis/ } \\
\text { Imóveis }\end{array}$ \\
\hline
\end{tabular}

Fonte: Pesquisa (2015).

No Quadro 6 está detalhado o modelo de nomenclatura padrão, citando quatro exemplos de formação de nomes de materiais. $O$ modelo de nomenclatura padrão atrelou o tipo de material com a matéria prima utilizada, as dimensões do produto e alguma característica particular. 
MELHORIA DE INDICADORES DE DESEMPENHO DE PRODUÇÃO EM UMA EMPRESA DE PEQUENO PORTE POR MEIO DE UM SISTEMA DE INFORMAÇÃO ERP̉ GRATUITO

Quadro 6: Nomenclatura padrão de materiais

\begin{tabular}{|c|c|c|c|c|}
\hline CATEGORIA & TIPO DE MATERIAL & MATÉRIA PRIMA & DIMENSÕES & $\begin{array}{c}\text { CARACTERÍSITICAS } \\
\text { PATICULARES }\end{array}$ \\
\hline \multirow{2}{*}{ MP - Metais } & $\begin{array}{c}\text { Tubo redondo } \\
\text { Chapa }\end{array}$ & $\begin{array}{c}\text { Alumínio } \\
\text { Alumínio }\end{array}$ & $\begin{array}{c}11 / 4^{\prime \prime} \times 1 / 16^{\prime \prime} \times 6000 \mathrm{~mm} \\
1.5 \times 1200 \times 1500 \mathrm{~mm}\end{array}$ & $\begin{array}{c}\text { LG6351-T6 } \\
5052-\mathrm{H} 34\end{array}$ \\
\hline \multirow{2}{*}{ MP - Fixadores } & Parafuso & Inox 304 & $\mathrm{M} 4 \times 12 \mathrm{~mm}$ & $\begin{array}{c}\text { Cabeça cilíndrica } \\
\text { Philips cabeça chata }\end{array}$ \\
\hline
\end{tabular}

Fonte: Pesquisa (2015).

Os exemplos citados no Quadro 6 mostram que, apesar de serem insumos com características funcionais diferentes, foi possível a formação de um nome padronizado.

Para a formação dos códigos dos materiais, utilizou-sede um modelo de cinco dígitos, em que os dois primeiros são letras do nome da categoria do produto e os três demais são números sequenciais. Finalizada a modelagem do agrupamento e nomenclatura dos materiais, estes foram codificados fisicamente dentro do estoque para a correta movimentação dos itens (entradas e baixas do estoque) no momento da sua separação para a produção.

Criados os grupos e codificações, ocorreu o cadastrado da antena PV215027 e seus componentes no sistema, bem como o cadastro das operações de produção envolvidas (soldagem, montagem, pintura e embalagem). Após realizados estes cadastros, foi dado por finalizado o processo de parametrização dos módulos de estoques e manufatura.

Para concluir a proposta do escopo do projeto, foi configurado o módulo de compras. A parametrização deste módulo consistiu em alguns cadastros contábeis e cadastros de fornecedores. Relativo aos cadastros de contabilidade, apesar deste módulo não fazer parte do escopo, foi necessário realizar a parametrização das contas contábeis para direcionamento dos inventários de materiais comprados dentro dos livros de estoques gerados pelo programa OpenERP. Como o sistema possui interligações entre os módulos, alguns cadastros se tornam pré-requisitos para o correto funcionamento do ciclo operacional, sendo obrigatórios executá-los.

Logo que finalizados, os cadastros gerais iniciaramas simulações. Assim, mediante a operação dosistema de informação, observou-se os movimentos gerados pelas emissões dos documentos denominados "ordens de produção", "cotações de compras" e lançamento das notas fiscais de fornecimento de insumos. As simulações do módulo de compras consistiram em criar as cotações pelo sistema com as matérias primas, emitindo o documento através do sistema e encaminhando o documento por e-mail para os fornecedores. Mediante a chegada dos materiais adquiridos, o gestor deu a entrada das notas fiscais no programa, o que gerouregistros de movimentações de entrada nos estoques.

No módulo de manufatura, as simulações foram realizadas, criando"ordens de produção". Os documentos emitidos com os itens da antena e seus processos de fabricaçãomostram as movimentações ocorridas no módulo de estoques, verificando a baixa das matérias primas que estão elencadas na ordem de produçãono momento da confecção da antenas e a entrada do produto finalizado no estoque, mediante o encerramento da ordem de produção no sistema.

Efetivadas as simulações, ocorreu uma reunião com os operadores a fim de visualizar o ciclo operacional completo dos módulos. O ciclo completo consistiu em cada usuário realizar a sua atividade chave dentro do ERP e analisar conjuntamente com os demais operadores as interações ocorridas entre os módulos a partir de uma tarefa executada, bem como a sequência

ReV. AdM. UFSM, SANTA MARIA, V. 11, EDIÇÃO ESPECIAL, P. 213-227, 2018 
de operações no momento que surge uma ordem de produção. Para os colaboradores, foi importante demonstrar o ciclo operacional completo, pois facilitou a compreensão da importância do trabalho de cada um dentro do ERP.

Ao final das simulações, foi realizada uma revisão das tarefas a fim de verificar o cumprimento dos objetivos e conferir a execução das atividades delegadas. Foram fornecidos formulários para cada usuário com as atividades pré-definidas, demonstrando as ações que o mesmo deveria executar, com seus respectivos prazos. Assim, desenvolveu-se um checklist relacionando as macro atividades do projeto e seus respectivos responsáveis, a fim de verificar as ações desenvolvidas e assegurar o êxito da operação. O Quadro 7 ilustra o checklist de entrega de atividades.

Quadro 7: Check list das Atividades para a Entrega do Sistema

\begin{tabular}{|l|l|c|}
\hline \multicolumn{1}{|c|}{ ATIVIDADE } & \multicolumn{1}{|c|}{ RESPONSÁVEL } & STATUS \\
\hline Carregamento de dados no sistema & Cada usuário é responsável pelo seu módulo & $100 \%$ \\
\hline Conferência das tarefas delegadas & Pesquisador & $100 \%$ \\
\hline Simulação individual & Pesquisador e usuários & $100 \%$ \\
\hline Simulação conjunta & Pesquisador e usuários & $100 \%$ \\
\hline Análise dos das dissonâncias da simulação & $\begin{array}{l}\text { Cada usuário anota o que falta para que sua área } \\
\text { esteja em conformidade com o padrão do sistema }\end{array}$ & $100 \%$ \\
\hline Ações corretivas & Usuário chave corrige os erros & $100 \%$ \\
\hline Revisão das ações corretivas & $\begin{array}{l}\text { Pesquisador revisa erros ocorridos após ações } \\
\text { corretivas }\end{array}$ & $100 \%$ \\
\hline
\end{tabular}

Fonte: Pesquisa (2015).

Conferidas as atividades do check-list, a implantação foi dada como por encerrada, iniciandoa fase de estabilização do ERP. Neste momento, o programa passou a fazer parte da rotina de trabalho dos colaboradores e foi considerado como entregue pelo pesquisador.

Após a implantação do ERP, a ordem de produção (OP) passou a ser o documento que rege a administração da produção e esta automatizou o processo de conferência de materiais (antes realizado por inspeção visual), pois desencadeou no módulo de estoques as reservas dos itens que compõea antena PV215027, mediante a emissão das OPs, verificando se os mesmos estavam presentes ou não no estoque.

$\mathrm{Na}$ etapa final do estudo,ocorreu a análise dos dados quantitativos, que consistiu no encerramento da coleta de dados e a sua tabulação para mensuração de indicadores de desempenho de produção. Nesta análise,foi identificado o comportamento dos indicadores ao longo dos 8 meses da aplicação do instrumento de coleta, auxiliando a compreensão dos impactos do processo de implantação do sistema ERP de gestão de produção na empresa.

Para a tabulação dos dados, foi utilizada planilha do Microsof Exce $\left.\right|^{\circledast}$ (versão 2013), onde foi analisada a progressão do desempenho de produção antes, durante e depois da implantação ERP, com o objetivo de visualizar se houve melhoria no desempenho de produção, evidenciando a eficácia do sistemana na gestão empresarial.

Como resultados, verificou-se que no mês de março, do total de pedidos emitidos da antena PV215027, a produção atrasou, em média, 4 dias. Nos meses de abril e maio, os atrasos médios caíram para 3,17 e 2,4 dias, por consequência da organização dos processos da empresa, durante o desenvolvimento da pesquisa, que tornou a produção mais eficiente.

Porém, nos meses de junho e julho os atrasos aumentaram, chegando ao pico máximo de 4,7 dias de atraso médio mensal. Este aumento foi uma resposta ao início do processo de implantação 
do sistema, que se estendeu nos meses de junho, julho e agosto, que tomou tempo dos colaboradores da empresa em função das adaptações necessárias à implantação do ERP e tornou a produção mais ineficaz. Na Figura 4, apresenta-se a mensuração do indicador de tempo médio de atraso de produção.

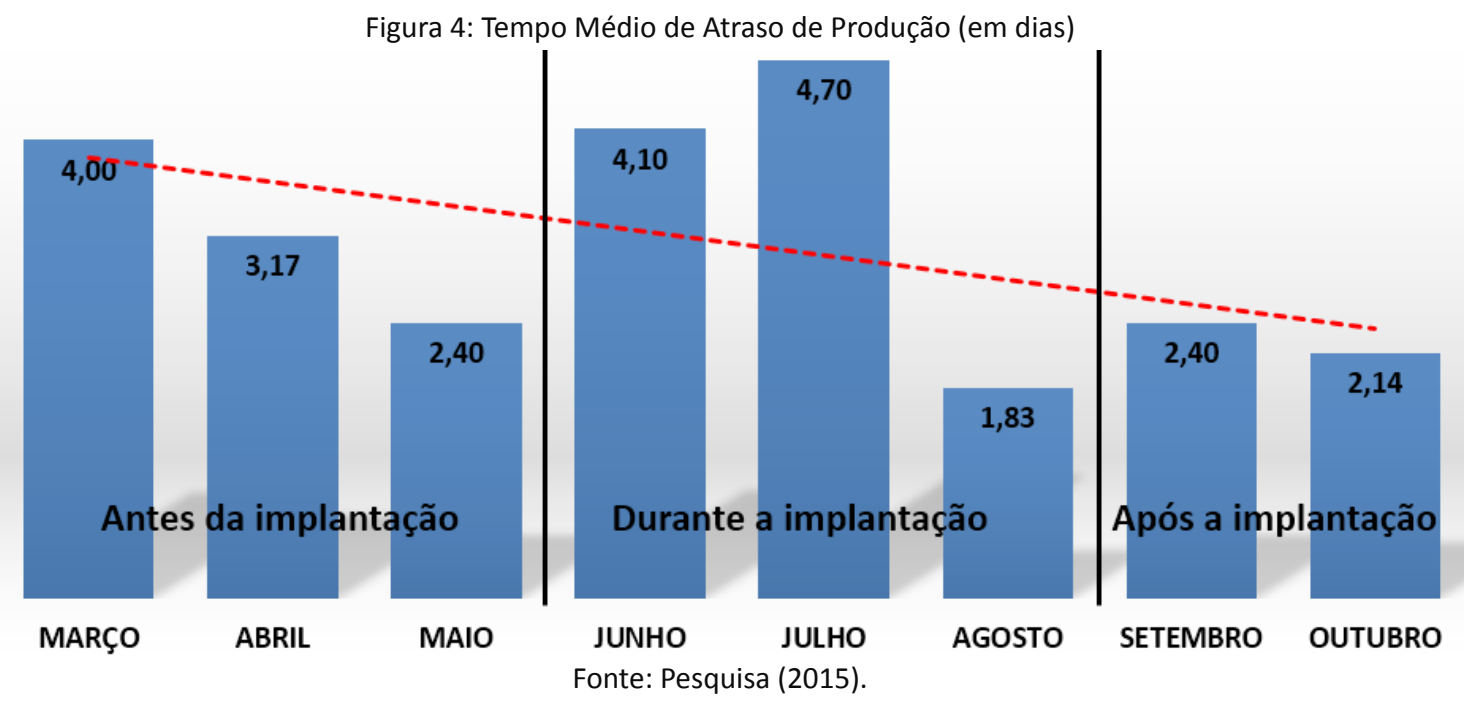

Nos meses subsequentes, o indicador apresentou queda, o que significou que os atrasos médios de pedido reduziram com a implantação do sistema. Nos meses de setembro e outubro os pedidos atrasaram, em média, 2,4 dias e 2,14 dias, respectivamente, o que representou uma redução significativa relativo ao início da aplicação da pesquisa, gerando um ganho de produtividade de 2 dias para a organização.

A média geral de dias de atrasos de pedidos de produção, em função da falta de materiais no estoque, foi de 3,04 dias de atraso. Os gestores da empresa desconheciam este número e através dos dados da pesquisa foi estipulado como meta obter zero dias de atraso de produção de pedidos, traçando-se ações de melhoria de gestão de processos relacionados ao PCP.

No que tange à quantidade de pedidos atrasados, a Figura 5 expõe que do total de pedidos da antena PV215027 ocorridos no mês de março de 2015, em média, 67\% obtiveram atrasos no início da produção em função da falta de itens no estoque.

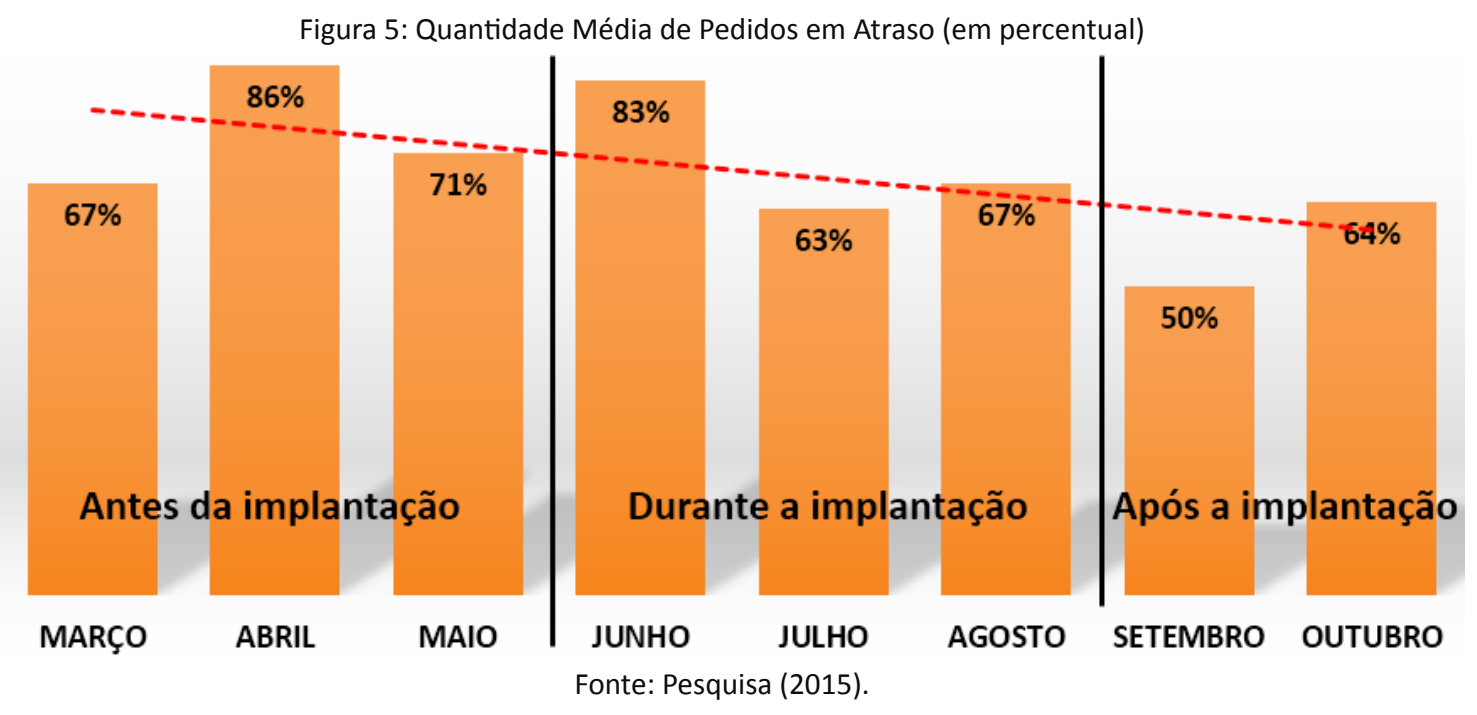


Nos meses subsequentes, os percentuais se elevaram chegando ao pico de $86 \%$ do total dos pedidos em atraso. Uma das hipóteses formuladas para este aumento de $19 \%$ é que, além da ineficácia do processo, também houve um aumento do volume de pedidos deste produto, prejudicando o índice. Nos meses posteriores à implantação do sistema ERP, o indicador apresentou melhora, sinalizado pela linha de tendência decrescente da Figura 5. No mês de setembro, o atraso chegou ao pico mínimo de $50 \%$ do total dos pedidos do mês, o que ainda representa um indicativo alarmante da gestão ineficaz de materiais.

Evidencia-se, por meio da mensuração dos indicadores, que o sistema ERP contribuiu positivamente com a empresa, realizando decréscimo de $36 \%$ da quantidade de pedidos atrasados e de dias de atraso de produção decorrentes da gestão de materiais. Portanto, é correto inferir que, neste caso, o sistema ERP cumpriu com o propósito de auxiliar na gestão empresarial, pois realizou melhorias nos indicadores de propostos.

Outro ganho para a empresa com a implantação de um ERP gratuito foi a economia direta com mensalidades e upgrades. Estima-se que a empresa deixou de gastar anualmente o valor de $\mathrm{R} \$ 78.000,00$, relativos às mensalidades que foram deixadas de pagar, enquanto utilizavao sistema proprietário da TOTVs e os upgrades que ficavam na faixa de $\mathrm{R} \$ 30.000,00$ ao ano.

\section{CONCLUSÕES}

A implantação ERP gratuito foi vantajosa para a organização, gerando informações importantes para o planejamento, controle e otimização de atividades de produção, além de automatizar, registrar e distribuir as informações a cada ocorrência da atividade para todos os usuários do sistema.

Evidenciou-se que foi atingidoo objetivo proposto para esta pesquisa, o qual consistiu em "implantar um sistema ERP gratuito em uma pequena empresa a fim de melhorar indicadores de produção". Os resultados dos indicadores mensurados apontaram queda de até 2 dias nos atrasos de produção após a implantação do ERP, bem como a redução de até $36 \%$ na quantidade de pedidos atrasados, concluindo-se que a aplicação do sistema otimizou a produtividade do empreendimento.

Relativo às análises qualitativas, o fato de implementar um padrão de gestão mais arrojado e inovador do o anterior empregado, também representou um desenvolvimento da gestão da organização pesquisada. Quanto aos impactos da melhoria da gestão da produção no resultado da empresa, o aumento de produtividade da operação trouxe benefícios além das linhas do chão de fábrica, como o aumento da satisfação dos clientes em função da redução dos atrasos no prazo de entrega dos produtos, impactando na empresa como uma vantagem competitiva.

A melhoria de produtividade também resultou em aumento da lucratividade da organização, pois com a redução do atraso a fábrica obteve uma maior vazão dos produtos confeccionados, aumentando o nível de faturamento da empresa, bem como a redução do custo geral de fabricação.

Outro benefício gerado se refere ao ganho dos colaboradores, pois existe, na empresa, a política de comissionamento sobre produtos faturados. Assim, uma maior produtividade representa maior giro de fabricação e, consequente, aumento das vendas, resultando em maior ganho salarial para os funcionários. Desse modo, deixar claro os benefícios adquiridos por meio do sistemaERP, auxiliou na adesão dos usuários e motivou a mudança da cultura organizacional, facilitando o processo de implantação do sistema.

Em resumo, a otimização da produtividade da empresa, por meio da implantação de um sistema ERP, trouxe benefícios múltiplos no caso da empresa pesquisada, sendo um exemplo que pode ser seguido por outras micro e pequenas empresas do Brasil. Considerando que $98 \%$ 
dos empreendimentos brasileiros são organizações enquadradas como MPEs, infere-se que a implantação de sistemas ERP gratuitos auxiliam no desenvolvimento econômico do país, pois estes auxiliam as organizações a melhorarem sua gestão e a se consolidarem no mercado.

Evidencia-se a importância do estudo para o meio acadêmico e para o meio empresarial, uma vez que este serve como base na elaboração de novas pesquisas, além deaprofundar o conhecimento sobre a gestão de sistemas ERP em pequenos negócios e a utilização de sistemas de informação gratuitos como uma alternativa às organizações com fortes contenções orçamentárias.

Como limitações da pesquisa, destaca-se a restrição de tempo para odesenvolvimento das atividades, o que obrigou o pesquisador a reduzir o escopo do projeto de implantação a um produto e a três módulos de operação do programa, bem como a falta de orçamento para investir em consultorias para aprimorar os treinamentos e desenvolvimento da equipe.

A fim de dar continuidade à pesquisa, propõe-se a ampliação do escopo de implantação para os demais produtos fabricados pela empresa, bem como expandir a implementação para outras funcionalidades do sistemacomo módulos financeiros, contábeis, custos e gestão de pessoas. Outra sugestão de continuidade do estudo é desenvolver a implantação de sistemas ERP gratuitos em outras empresas de pequeno porte, comparando os resultados entre diferentes tipos de negócios e diferentes culturas organizacionais.

\section{REFERÊNCIAS}

CAllado, A. L. C.; CAllado, A. A. C.; AlMEIDA, M. A. Análise dos Indicadores e Ações de Organizações Agroindustriais Segundo as Perspectivas do Balanced Scorecard. Revista Universo Contábil, Blumenau, v. 3, n. 3, p. 38-53, 2007.

CHOPRA, S.; MEINDL, P. Gerenciamento da Cadeia de Suprimentos - Estratégia, Planejamento e Operação. Prentice Hall, 2003.

DAVENPORT, T. H. Reengenharia de processos: Como inovar na empresa através da tecnologia da informação. 2. ed. Rio de Janeiro: Campus, 1994.

ESTEVES, J.; PASTOR, J. A. AnERP lifecycle-based research agenda. 1st International Workshop in Enterprise Management \& Resource Planning,1999a.

ESTEVES, J.; PASTOR, J. A. El ciclo de vida de los sistemas ERP. Revista Datamation, versão espanhola, edição especial, 1999b.

FLEURY, A. C. C. Metodologia de pesquisa em engenharia de produção e gestão de operações. Atlas, 2012.

GIL, A. C. Métodos e técnicas de pesquisa social. Atlas, 2010.

MACHADO, H. V. Empreendedorismo e franchising: uma combinação que garante a sobrevivência? Revista de Administração Mackenzie, São Paulo, v. 11, n. 4, 2010.

MARQUES, E. S; OLIVEIRA, M. L. A. de. Balanced Scorecard: ferramenta estratégica e competitiva aplicável às bibliotecas. Revista Brasileira de Biblioteconomia e Documentação, v. 4, n. 2, p. 105-115, 2008.

NASCIMENTO, M. et al. Fatores determinantes da mortalidade de micro e pequenas empresas da região metropolitana de Florianópolis sob a ótica do contador. Revista Eletrônica de Estratégia \& Negócios,v. 6, n. 2, p. 244-283, 2013. 
NORRIS, G.; HURLEY, J. R. E-business e ERP: transformando as organizações. Qualitymark Editora Ltda, 2001.

O'BRIEN, J. A.; MARAKAS, G. M. Administração de Sistemas de Informação. Porto Alegre: AMGH, 2013.

PADILHA, T. C. C.; MARINS, F. A. S. Sistemas ERP: características, custos e tendências. Revista Produção, v. 15, n. 1, p. 102-113, 2005.

SALES, R. L.; BARROS, A. A.; PEREIRA, C. M. M. de A. Fatores condicionantes da mortalidade dos pequenos negócios em um típico município interiorano brasileiro. Revista da micro e pequena empresa, v. 5, 2011.

SANTINI, S. et al. Fatores de mortalidade em micro e pequenas empresas: um estudo na região central do Rio Grande do Sul. Revista Eletrônica de Estratégia \& Negócios, v. 8, n. 1, p. 145-169, 2015.

SANTOS, J. G.; Planejamento e controle da produção de havaianas: um estudo de caso na Alpargatas de Campina Grande/PB. Revista Gestão Industrial, v. 9, n. 3, 2013.

SEBRAE (2013). Anuário do trabalho na micro e pequena empresa: 2010-2011. 4. ed. Departamento Intersindical de Estatística e Estudos Socioeconômicos[responsável pela elaboração da pesquisa, dos textos, tabelas e gráficos]. Brasília, DF; DIEESE. Disponível em: <http:// www.sebrae.com.br/Sebrae/Portal\%20Sebrae/Anexos/Anuario\%20do\%20Trabalho\%20Na\%20 Micro\%20e\%20Pequena\%20Empresa_2013.pdf>. Acesso em: dez. 2014.

STAKE, R. E. Pesquisa qualitativa/naturalista: problemas epistemológicos. Educação e Seleção, n. 07, p. 19-27, 2013.

TEIXEIRA, J. E. Políticas de estímulo à inovação em micro e pequenas empresas: contribuições do Programa Agentes Locais de Inovação (Brasil) e da Rede PME Inovação (Portugal). Tese.2017.

THOMAS, J. R.; NELSON, J. K.; SILVERMAN, S. J. Métodos de pesquisa em atividade física. 5. Ed. Artmed, 2007.

TOZONI-REIS, M. F. de C. A pesquisa-ação-participativa em educação ambiental: reflexões teóricas. Annablume, 2007.

TRIPP, D. Pesquisa-ação: uma introdução metodológica. Educação e pesquisa, v. 31, n. 3, p. 443-66, 2005.

TURBAN, E. et al. Tecnologia da Informação para Gestão: Transformando os Negócios na Economia Digital. 6 ed. Bookman, 2010.

VOLLMANN, T. et al. Sistemas de Planejamento e Controle da Produção para gerenciamento da cadeia de suprimentos. São Paulo: Bookman, 2006.

WOOD JR., T.; CALDAS, M. P. Modas e modismos em gestão: pesquisa exploratória sobre adoção e implementação de ERP. In: ENCONTRO NACIONAL DOS PROGRAMAS DE PÓS-GRADUAÇÃO EM ADMINISTRAÇÃO - ENANPAD, 23, 1999, Foz do Iguaçu. Anais. Rio de Janeiro: Anpad, 1999.

YIN, R. K. Estudo de caso: planejamento e métodos. 4. ed. Porto Alegre: Bookman, 2010.

ZWICKER, R.; SOUZA, C. A. de. Sistemas ERP: conceituação, ciclo de vida e estudos de casos comparados. Sistemas ERP no Brasil: teoria e casos. São Paulo: Atlas, p. 63-87, 2003. 